\title{
Attitudes of Sport Science Students Regarding to Gender Roles
}

\author{
Nedim Malkoc \\ University of Health Sciences, Department of Exercise and Sports Sciences, Turkey. \\ Email:drmallocnedim@gmail.com Tel: +905414553988
}

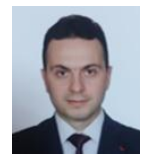

\begin{abstract}
Social gender is the difference that gender creates in a society, it is related to how one thinks of him or herself, how him or her interacts with others, social opportunities, professions, family roles, and the roles allowed for men and women. There is pluralist participation and a sense of justice in the philosophy of sports. In this context, all stakeholders (athletes, coaches, assistants, etc.) involved in sports activities are expected to evaluate and interpret sports activities in this context. The research was carried out using quantitative research method. A total of 318 students from the School of Physical Education and Sports (fourth grade) of Kastamonu University participated in the study. Perception Gender Scale consisting of 1 dimensions and 25 items, created by Altinova and Duyan (2013) was used as measurement tool. High average score of the scale indicates the positive perception of society gender roles. The data were found to be normally distributed and parametric test methods were used. According to results of the research conducted, the perceptions of gender of sports science students are at a medium level. In addition, gender perceptions of female sports science students were differentiated from male sports science students. The perceptions of gender did not differ among sports science students within the scope of the departments they received education. In addition, a low level of negative correlation was found between the ages of sports science students and their gender perceptions.
\end{abstract}

Keywords: Attitudes, College, Gender, Roles, Students, University.

Citation | Nedim Malkoc (2020). Attitudes of Sport Science Students Regarding to Gender Roles. Asian Journal of Education and Training, 6(3): 456-460.

History:

Received: 21 April 2020

Revised: 26 May 2020

Accepted: 28 June 2020

Published: 7 July 2020

Licensed: This work is licensed under a Creative Commons

Attribution 3.0 License (cc))

Publisher: Asian Online Journal Publishing Group
Funding: This study received no specific financial support

Competing Interests: The author declares that there are no conflicts of interests regarding the publication of this paper.

Transparency: The author confirms that the manuscript is an honest, accurate, and transparent account of the study was reported, that no vital features of the study have been omitted; and that any discrepancies from the study as planned have been explained.

Ethical: This study follows all ethical practices during writing.

\section{Contents}

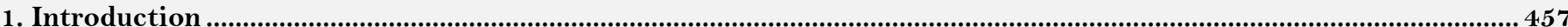

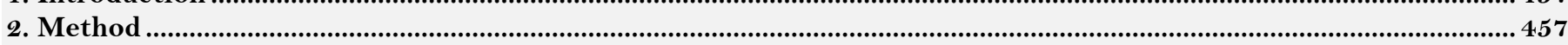

3. Findings

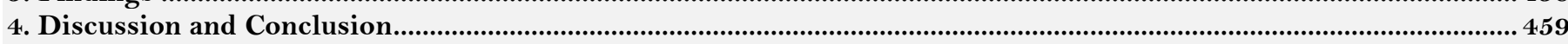

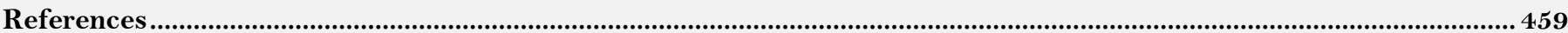




\section{Contribution of this paper to the literature}

The concept of gender perception is not one of the subjects that do not attract much attention in the field of sports sciences. As a result of the research carried out in this context, it is important to examine the gender perceptions of university student youth. It is expected to be a resource for similar researches in the field of sports sciences and to positively affect the concept of gender equality which is socially important.

\section{Introduction}

When the concept of gender is evaluated physiologically, it is about whether the individual is male or female (Manning, Bernhard, \& Robert, 2018; Vatandaş, 2007). In addition, when the concept of gender is examined sociologically, it expresses the place of men or women in society, their duties and responsibilities, in other words, their role in the society (Ozaydinlik, 2014). Social gender is the difference that gender creates in a society, it is related to how one thinks of him or herself, how he interacts with others, social opportunities, professions, family roles, and the roles allowed for men and women (Guzura, 2017).

Gender divisions shape the lives of both women and men, and this diversity is more than just difference. Therefore, the way, proportion, representation and visibility of women and men in a society are affected by the perception of gender that is valid in that society (Ongen \& Aytaç, 2013). Although the concept of gender equality has become prominent in social life recently, roles given to men in patriarchal societies may be more valuable than roles given to women. According to the social learning theory, parental attitudes have a significant effect on the child's gaining roles suitable for gender. The results of many studies show that fathers behave in the direction of a more traditional gender role than mothers and be gentle, understanding and helpful to girls; it has shown that it teaches boys autonomy, leadership and assertiveness (Gumus, 2019).

In Turkish society, which is partially separated from western societies with its patriarchal social structure (Kıran, 2017) while gender roles are sharply separated, this distinction is not clear in another segment. In other words, although some of the society thinks that they have determined the duties and roles given to men and women, the concept of gender equality is widely accepted for some of the society (Oz, 2018).

Research on sports and gender-related content has been increasing in recent years (Adriaanse \& Schofield, 2014; Archer \& McDonald, 1990; Cunningham, 2008; Derom et al., 2019; Huggins \& Randell, 2007; Klomsten, Skaalvik, \& Espnes, 2004; Van Ingen, 2003). Seeing sports as an activity specific to men by integrating it with the athletic structure of men is a product of patriarchal understanding that accepts men as the sovereign in society, and there is a close relationship between the gender roles of this understanding that prevails in society and the sports experiences and sports experiences of women and men (Koca, 2006).

There is pluralist participation and a sense of justice in the philosophy of sports. In this context, all stakeholders (athletes, coaches, managers, assistants, etc.) involved in sports activities are expected to evaluate and interpret sports activities in this context. In addition, sports activities are seen as a way of ensuring sociological equality of women and men (Beal, 1994). Nevertheless, in the sports environment, there is also a point of view of humiliating women athletes and seeing a sports area of sports activities for men (Hannon, Soohoo, Reel, \& Ratliffe, 2009). In another perspective (Gill, 2002) stated that gender should be evaluated in the context of broader social diversity, which includes analysis of other ideologies (eg race, social class). Prejudices about gender also affect sports activities, which is an important communication process, negatively. Communication skills of a good sports trainer are expected to be high (Sunay, Cengiz, \& Yaşar, 2017).

Until the early 1900s, sports activities were concerned with the evaluation of distant and leisure times for women, rather than competitive sports activities (Bell, 2007). However, with the beginning of the 20th century, the increase and change in free time periods of human life's and leisure consumption, it is seen that women are in sports activities and competitive environment (Hargreaves, 2002). It is thought that sports media's work on gender equality plays an important role in this process. Within the scope of sportive activities, media literacy is important in this process (Erdeveciler, Uyar, Sunay, \& Atl, 2019). In addition, many sports advertisements bring male gender to the fore and can undermine the gender equality in the sports environment (Balci \& Özgen, 2017). But still it is possible to determine that the concepts of gender perception and sports have been evaluated with a different and positive perspective recently.

In the light of all this information, individuals who are studying sports science and who are future sports scientists should be formed within the scope of free and equitable (fair) thinking. Nevertheless the last year of university importance can be stressful for university students (Yasar \& Turgut, 2020). In this context, gender prejudices may be high among senior students who are educated in the field of sports sciences. The aim of the research is to determine the gender roles perceptions of senior sports science students and to examine them according to different variables (Sex Age, Department).

Hypothesis 1: There is a difference between university students' sex and perception of the gender roles.

Hypothesis 2: There is a difference between university students' departments and perception of the gender roles.

Hypothesis 3: Participant university students have a positive attitude towards society gender roles.

Hypothesis 4: There is a positive relationship between university students' age and perception of the gender roles.

\section{Method}

\subsection{Participants}

The research was carried out using quantitative research method. A total of 318 students from the School of Physical Education and Sports (fourth grade) of Kastamonu University participated in the study. As a sampling method, simple random sampling method was preferred. Characteristics of the sample is given in Table 1. 


\begin{tabular}{c|c|c|c}
\hline \multicolumn{4}{c}{ Table-1. Characteristics of the sample. } \\
\hline Personal Information & Groups & Frequency (f) & Percentage (\%) \\
\hline Age & M=23.01 & 318 & 100 \\
\hline \multirow{2}{*}{ Gender } & Male & 199 & 62,6 \\
\cline { 2 - 4 } & Female & 119 & 37,4 \\
\hline \multirow{2}{*}{ Department } & P.E.T.E & 65 & 20,4 \\
\cline { 2 - 4 } & Coaching Education & 108 & 34,0 \\
\cline { 2 - 4 } & Sport mangement & 145 & 45,6 \\
\hline Total & \multicolumn{2}{|}{318} \\
\hline
\end{tabular}

2.2. Data Collection Tool in the Research

Perception Gender Scale consisting of 1 dimensions and 25 items, created by Altinova and Duyan (2013) was used as a measurement tool. High average score of the scale indicates the positive perception of society gender roles. Data collection tool was a self-report scale with 5 Likerts. Data collection was carried out via Google Forms. Expressions in the scale, I fully agree "5 points (5.00-4.20)", I agree "4 points (4.19-3.40)", I am undecided "3 points (3.39-2.60)", disagree " 2 points (2.59-1.80)", I strongly disagree The $\mathrm{n}-1 / \mathrm{n}$ formula was used to determine the score ranges $(5-1 / 5=4 / 5=0.80)$.

\subsection{Data Collection and Analysis}

According to the obtained kurtosis and skewness values, the data were found to be normally distributed and parametric test methods were used. The reliability value of the research data was tested with Cronbach Alpha value and it was found 0.83 for the whole scale. The study was conducted following the Declaration of Rickham (1964).

\section{Findings}

The mean score and skewness kurtosis values obtained according to the results of the research are given in Table 2 .

Table-2. Scale scores and skewness kurtosis values.

\begin{tabular}{c|c|c|c|c}
\hline \multicolumn{6}{c|}{ Tale } & $\mathbf{X}$ & Std. Deviation & Skewness & Kurtosis \\
\hline Gender Perception Scale & 3.21 & .546 &, 187 & 1.837 \\
\hline
\end{tabular}

According to the analysis of the data, the mean score obtained by the participants from the Gender Perception Scale scale is 3.21. In other words, the Gender Perception levels of the participants were moderate.

\begin{tabular}{c|c|c|c|c|c|c}
\multicolumn{2}{c}{ Table-3. T-Test Results according to the gender variable of the participants. } \\
\hline Scale & Gender/Sex & $\mathbf{N}$ & $\mathbf{X}$ & $\mathbf{S s}$ & $\mathbf{p}$ & Difference \\
\hline \multirow{2}{*}{ Gender Perception Scale } & Male & 199 & 3.32 & .60 & \multirow{2}{*}{$.000^{*}$} & \multirow{2}{*}{$1<2$} \\
\cline { 2 - 5 } & Female & 119 & 3.03 & .37 & & \\
\hline Note: $\mathrm{p}<0.05$.
\end{tabular}

According to the Gender/Sex variable in Table 3, there was a statistical difference in the mean score of the scale. According to the results, the average score of male participants' obtained from the Gender Perception Scale scale was higher than female participants. In other words, Gender Perception Scale of male participants was found to be significantly higher than female participants.

Table-4. Anova Results According to the department variable of the participants.

\begin{tabular}{|c|c|c|c|c|c|c|}
\hline Scale & Department & $\mathbf{N}$ & $\bar{X}$ & Ss. & $\bar{p}$ & Difference \\
\hline \multirow{3}{*}{ Gender Perception Scale } & P.E.T.E. & 65 & 3.20 & .46 & \multirow{3}{*}{.407} & \multirow{3}{*}{-} \\
\hline & Coaching Education & 108 & 3.16 & .53 & & \\
\hline & Sport Management & 145 & 3.26 & .58 & & \\
\hline
\end{tabular}

Note: $\mathrm{p}<0.05$.

According to the department variable in Table 4, there was not any statistical difference in mean scores of scale. According to the results, the participants with the highest average of the Sport management department and the participants with the lowest average were of the coaching education department.

\begin{tabular}{l|l|c|c}
\multicolumn{2}{c}{ Table-5. Correlation analysis for participants' age and scale scores. } \\
\hline \multirow{2}{*}{ Age } & Pearson Correlation & Age & Scale \\
\cline { 2 - 4 } & Sig. (2-tailed) & 1 &,- 007 \\
\cline { 2 - 4 } & $\mathrm{N}$ & &, 903 \\
\hline \multirow{2}{*}{ Scale } & Pearson Correlation & 318 & 318 \\
\cline { 2 - 4 } & Sig. (2-tailed) &,- 007 & 1 \\
\cline { 2 - 4 } & $\mathrm{N}$ &, 903 & 318 \\
\hline
\end{tabular}

The results of Gender Perception Scale according to the age variable of the participants were given in Table 5. According to the results a low negative correlation was found between the participants' ages and Gender Perception. 


\section{Discussion and Conclusion}

As a result of the research, it was determined that the Gender Perception Scale level of the participating students was moderate (3.21). The high score obtained from the scale indicates negative gender perception, and the low score indicates positive gender perception. In the research conducted by Ozpulat (2017) gender perceptions of university students were examined. According to the results of the research, gender perceptions of the participant university students were determined at a medium level. In this context, the results of this research and the research conducted by Özpulat show similarity within the scope of the mean score. Another similar study was done by (Vefikuluçay, Zeyneloğlu, Eroğlu, \& Taşkin, 2007). According to the results of the research, the gender groups of the university senior students were found higher if they are traditional. In this context, there seems to be a difference between this research and the results of the research conducted by Vefikuluçay et al. The differences in the social structure in different geographical regions and the role between men and women can be shown as the reason of the results of the research in the same culture difference.

According to the results of the research, a statistically significant difference was found in the gender variable of the participants. According to this difference, gender perceptions of female participants showed a positive difference compared to male students. In the study conducted by Pesen, Kara, Kale, and Abbak (2016) the gender perceptions of university students were examined according to the gender variable of the participants. In this context, it is seen that there is a similarity between this research and the results of the research conducted by Pesen and his friends by gender. Another study on this subject has been examined by Ongen and Aytaç (2013) the gender perceptions of university students. According to the results of the research, gender perceptions of female participants were found to be higher than male students. In this context, it is seen that there is a similarity between the result of the research conducted by Öngen and Aytaç and the gender variable. In the researches about gender, the reason and desire of the female participants to have gender equality can be shown as a reason as the reason why the female participants are separated from the male participants at a positive level.

There was no statistically significant difference in the department variable of the participants according to the research results. The lack of differences according to the department variable of the participants can be shown as the reason why the participants come from a similar cultural structure and have the same generation habits. According to the results of the research, a low negative correlation was found between the participants' age variable and their gender perceptions.

According to the results of the research, a low negative correlation was found between the participants' age variable and their society gender perceptions. In the research conducted by Karasu, Göllüce, Güvenç, and Çelik (2017) the attitudes of university students towards gender roles were examined. According to the results of the research, a significant difference between the groups was determined within the age variable of the participants. In this context, no significant difference was found between the results of this research and the results of the research conducted by Karasu and Golluce by age variable.

In conclusion, according to the results of the research conducted, the perceptions of gender of sports science students are at a medium level. In addition, gender perceptions of female sports science students were differentiated from male sports science students. The perceptions of gender did not differ among sports science students within the scope of the departments they received education. In addition, a low level of negative correlation was found between the ages of sports science students and their gender perceptions.

\section{References}

Adriaanse, J., \& Schofield, T. (2014). The impact of gender quotas on gender equality in sport governance. Journal of Sport Management, 28(5), 485-497.Available at: https://doi.org/10.1123/jsm.2013-0108.

Altinova, H. H., \& Duyan, V. (2013). Validity reliability study of social gender perception scale. Journal of Society \& Social Work, $24(2), 9-22$.

Archer, J., \& McDonald, M. (1990). Gender roles and sports in adolescent girls. Leisure Studies, 9(3), 225-240.Available at: https://doi.org/10.1080/02614369000390191.

Balci, V., \& Özgen, C. (2017). What sports advertising tell to us? Semiotic analysis. Journal of Education and Training Studies, 5(6), 2432.Available at: https://doi.org/10.11114/jets.v5i6.2387.

Beal, C. R. (1994). Boys and girls: The development of gender roles (pp. 133). New York: McGraw-Hill.

Bell, R. C. (2007). A history of women in sport prior to title IX. The Sport Journal, 10(2), 1-8.

Cunningham, G. B. (2008). Creating and sustaining gender diversity in sport organizations. Sex Roles, 58(1-2), 136-145.Available at: https://doi.org/10.1007/s11199-007-9312-3.

Derom, I., Schaillée, H., Straume, S., Rambaldo, H., Renfree, G., \& Vanessa, J. (2019). Educating generation z about gender equality in sport. Paper presented at the Women in Sport and Exercise 2019 Conference: Pushing the Boundaries, 11 th - 12th June 2019, St Mary's University, Twickenham.

Erdeveciler, Ö., Uyar, Y., Sunay, H., \& Atll, A. (2019). Determination of faculty of sport sciences student's media literacy levels (Example of Ankara Province). OSR Journal of Sports and Physical Education (IOSR-JSPE) 4(5), 51-60.

Gill, D. (2002). Gender and sport behavior. In T. Horn (Ed.), Advances in sport psychology (pp. 355-375). Champaign, IL: Human Kinetics.

Gumus, Z. (2019). Determining university students' attitudes towards gender roles. Turkey Journal of Integrative Psychotherapy, 2(3), $31-47$.

Guzura, T. (2017). An overview of issues and concepts in gender mainstreaming. Afro Asian Journal of Social Sciences, 8(1), 1-28.

Hannon, J., Soohoo, S., Reel, J., \& Ratliffe, T. (2009). Gender stereotyping and the influence of race in sport among adolescents. Research Quarterly for Exercise and Sport, 8O(3), 676-684.Available at: https://doi.org/10.1080/02701367.2009.10599608.

Hargreaves, J. (2002). Sporting females: Critical issues in the history and sociology of women's sport. USA-New York: Routledge.

Huggins, A., \& Randell, S. (2007). The contribution of sports to gender equality and women's empowerment. Paper presented at the International Conference on Gender Equity on Sports for Social Change, Kigal.

Karasu, F., Göllüce, A., Güvenç, E., \& Çelik, S. (2017). University students' attitudes towards gender roles [The attitudes of the university students 'regarding the gender roles]. SDU Journal of Health Sciences, 8(1), 21-27.

Kıran, E. (2017). Gender roles and child marriage in Turkey. Paper presented at the ICOMEP International Congress of Management, Economy and Policy 2017

Klomsten, A. T., Skaalvik, E. M., \& Espnes, G. A. (2004). Physical self-concept and sports: Do gender differences still exist? Sex Roles, 5o(12), 119-127.

Koca, C. (2006). Gender relations in physical education and sport. Hacettepe Journal of Sports Science, 17(2), 81-99.

Manning, J. T., Bernhard, F., \& Robert, T. (2018). The biology of human gender. Encyclopedia of evolutionary psychological science. New York: Springer, Cham.

Ongen, B., \& Aytaç, S. (2013). Attıtudes of unıversıty students regardıng to gender roles and relatıonshıp with lıfe values. Journal of Sociological Studies 48(2), 1-18. 
Oz, H. G. (2018). Gender perception of conservative fashıon magazıne on the context of plural modernity theory. The Journal of International Social Research, $11(57), 289-296$.

Ozaydinlik, Y. (2014). Women in Turkey on the basis of gender and education. Journal of Social Policy Studies, 14, 93-1 12.

Ozpulat, F. (2017). The relationship between nursing students' violent tendencies and gender perceptions. Başkent University Journal of Health Sciences Faculty-BÜSBID, 2(2), 151-165.

Pesen, A., Kara, İ., Kale, M., \& Abbak, B. S. (2016). Examining university students' perceptions of gender and their conflict and violent awareness levels. International Journal of Society Researches 6(11), 325-339.

Rickham, P. P. (1964). Human experimentation. Code of ethics of the world medical association. Declaration of Helsinki. British Medical Journal, 2(5402), 177-177.

Sunay, H., Cengiz, R., \& Yaşar, O. M. (2017). Investigation of the communication skills levels of football trainers according to university football team sports' perceptions. IOSR Journal of Sports and Physical Education (IOSR-JSPE), 4(1), 49-53.Available at: https://doi.org/10.9790/6737-04014953.

Van Ingen, C. (2003). Geographies of gender, sexuality and race: Reframing the focus on space in sport sociology. International Review for the Sociology of Sport, 38(2), 201-2 16.Available at: https://doi.org/10.1177/1012690203038002004.

Vatandaş, C. (2007). Social gender and the perception of gender rolls. Journal of Sociological Studies, 35, $29-56$.

Vefikuluçay, A. G. D., Zeyneloğlu, A. G. S., Eroğlu, K., \& Taşkin, L. (2007). Perception of and views on gender roles of senior students enrolled at Kafkas university. Hacettepe University Journal of Nursing Faculty, 14(2), 26-38.

Yasar, O. M., \& Turgut, M. (2020). Unemployment anxiety of last year college students. Cypriot Journal of Educational Sciences, 15(1), 5664.Available at: https://doi.org/10.18844/cjes.v15i1.4588. 